\title{
Foreskin care in childhood
}

\author{
Ryan McLarty MD, Darcie Kiddoo MD MPH
}

Cite as: CMAJ 2019 April 1;191:E365. doi: 10.1503/cmaj.180875

CMAJ Podcasts: author interview at https://soundcloud.com/cmajpodcasts/180875-five

\section{1}

\section{Rates of neonatal circumcision are declining in Canada}

Knowledge of foreskin care is important for both practitioners and parents. Physiologic phimosis (nonretractable foreskin) is normal in childhood. At birth, the inner foreskin is fused to the glans penis; this is termed "physiologic" and rarely requires treatment. Pathologic phimosis occurs in less than $2 \%$ of boys and presents as a sclerotic white ring at the foreskin tip on clinical examination. ${ }^{1}$ Lichen sclerosus, a form of pathologic phimosis related to chronic skin inflammation, is rarely seen in the first few years of life and results in substantial, progressive scarring that can involve the urethra. ${ }^{2}$

2

\section{Physiologic phimosis decreases with age}

Adhesions between the inner and outer foreskin release over time from repeated reflex erections and smegma collection. ${ }^{1}$ Physiologic phimosis exists in about $50 \%$ of 7 -year-old boys and decreases to less than $10 \%$ by age $13 .^{3}$

\section{3}

\section{Retraction of physiologic phimosis should not be forced}

When performed by parents or practitioners, retraction of physiologic phimosis can cause unnecessary discomfort, microscopic tearing and scarring. Ballooning of the foreskin with urination is benign and is not associated with obstruction. ${ }^{4}$ The best treatment of physiologic phimosis is watchful waiting. ${ }^{1}$

4

\section{Routine foreskin care can prevent problems}

Along with testicular self-examination, boys should be taught foreskin care to prevent infections. This involves gentle retraction during voiding to prevent urine pooling, and cleaning during bathing with soap and water. ${ }^{1}$ Avoiding paraphimosis (foreskin pushed above the glans penis, resulting in edema) is critical; if paraphimosis occurs, it requires urgent medical attention.

\section{Physiologic phimosis with complications or pathologic phimosis should prompt treatment}

Physiologic phimosis with recurrent urinary tract infections, balanoposthitis (inflammation of the entire foreskin and glans penis) or persistence of phimosis beyond age 10 years should prompt medical therapy and possible urologic referral. ${ }^{1}$ Treatment involves a topical steroid cream $(0.1 \%$ betamethasone) applied to the distal foreskin with gentle retraction for up to 8 weeks (70\%$80 \%$ success rate, with similar efficacy from less potent steroids) ${ }^{1,5}$ Pathologic phimosis may be treated medically initially and closely monitored by a urologist. The efficacy of medical treatment is lower for pathologic phimosis than for physiologic phimosis, and patients who do not respond to medical treatment require circumcision. ${ }^{1}$ Lichen sclerosus may be treated with a short course of steroids but often requires circumcision. ${ }^{2}$

\section{References}

1. Dave S, Afshar K, Braga LH, et al. Canadian Urologic Association guideline on the care of the normal foreskin and neonatal circumcision in Canadian infants. Can Urol Assoc J 2017; 12:E76-99.

2. Folaranmi SE, Corbett HJ, Losty PD. Does application of topical steroids for lichen sclerosus (balanitis xerotica obliterans) affect the rate of circumcision? A systematic review. J Pediatr Surg 2018;53:2225-7.

3. Hsieh TF, Chang $\mathrm{CH}$, Chang SS. Foreskin development before adolescence in 2149 schoolboys. Int J Urol 2006; 13:968-70

4. Babu R, Harrison SK, Hutton KA. Ballooning of the foreskin and physiological phimosis: Is there any evidence of obstructed voiding? BJU Int 2004;94:384-7.

5. Lund L, Wai KH, Mui LM, et al. An 18-month follow-up study after randomized treatment of phimosis in boys with topical steroids vs. placebo. Scand J Urol Nephrol 2005;39:78-81.

Competing interests: None declared.

This article has been peer reviewed.

Affiliations: Division of Urology (McLarty), and Department of Surgery (Kiddoo), University of Alberta, Edmonton, Alta.

Correspondence to: Darcie Kiddoo,dkiddoo@ ualberta.ca

CMAJ invites submissions to "Five things to know about ..." Submit manuscripts online at http://mc.manuscriptcentral.com/cmaj 